\title{
Estimation of antioxidant activity of different mixed herbal infusions using attenuated total reflectance Fourier transform infrared spectroscopy and chemometrics
}

\author{
Aikaterini Venetsanou', Eirini Anastasaki ${ }^{1}$, Chrysavgi Gardeli ${ }^{2}$, Petros A. Tarantilis ${ }^{1}$, Christos S. Pappas ${ }^{1 *}$ \\ ${ }^{1}$ Department of Food Science \& Human Nutrition, Laboratory of Chemistry, School of Food, Biotechnology and Development, Agricultural \\ University of Athens, 75 lera Odos, 11855 Athens, Greece, ${ }^{2}$ Department of Food Science \& Human Nutrition, Laboratory of Food Chemistry \\ and Analysis, School of Food, Biotechnology and Development, Agricultural University of Athens, 75 lera Odos, 11855 Athens, Greece
}

\section{A B S T R A C T}

\begin{abstract}
Antioxidant activity of 19 different mixed herbal infusion as it was calculated by 2,2-diphenyl-1-picrylhydrazyl (DPPH) and 2,2'-azinobis(3-ethylbenzothiazoline-6-sulfonic acid) (ABTS) assays was correlated using attenuated total reflectance Fourier transform infrared spectroscopy (ATR-FTIR) and chemometrics. The spectral region $1538-843 \mathrm{~cm}^{-1}$ in $2^{\text {nd }}$ derivative mode and the partial least squares (PLS) regression were used. The correlation coefficient, the root-mean-square error of calibration (RMSEC) and the root-mean-square error of prediction (RMSEP) for the DPPH assay were $0.97,130$ and 118 respectively. The corresponding values for the ABTS assay were $0.99,148$ and 121 . The above results show that it is possible to estimate the antioxidant activity according to DPPH and ABTS assays of different mixed herbal infusions using ATR-FTIR spectroscopy. Furthermore the proposed methods are simple, rapid and economical.
\end{abstract}

Keywords: Antioxidant activity; ATR-FTIR; Chemometrics; Herbal infusions; PLS

\section{INTRODUCTION}

Free radicals are products of oxygen and nitrogen that come from the metabolic paths. The excessive amount of these free radicals is the cause of chronic diseases in human (Dhar et al., 2012; Aktumsek et al., 2013). Antioxidants in food play an important role for human's health since the scientific community has proven that they can reduce the risk of chronic diseases such as cancer, heart disease and Alzhemier's disease (Aktumsek et al., 2013; Rautiainen et al., 2013; Saeidnia and Abdollahi, 2013). Phenolic compounds are responsible for the antioxidant activity and the main sources of them are fruit, vegetables, legumes, fats/oils and herbal infusion (Dhar et al., 2012; Reutenbach and Venter, 2013; Lou et al., 2014). The last years it has been found that the consumption of herbal infusions made of a great variety of herbs such as oregano, sage, rosemary etc., can be very helpful for someone's health as far as the antioxidant intake is concerned (Atoui et al., 2005; Boskou 2006; Pincemail et al., 2012).

There are many assays for the determination of antioxidant activity. The 2,2-diphenyl-1-picrylhydrazyl (DPPH) (Brand-Williams and others 1995) and 2,2'-azinobis(3-ethylbenzothiazoline-6-sulfonic acid) (ABTS) methods (Re et al.,1999) were used widely.

Fourier transform infrared spectroscopy (FTIRS) is recognized as a very good analytical tool when it combined with various statistical methods (Fagan et al., 2007; Karoui et al., 2010; Khanmohammadi and Garmarudi, 2011; Ferreira et al., 2014). In recent years more publications are referenced in the statistical analysis of infrared Fourier transform (FT-IR) spectroscopic data for the study of herbs (Fu et al., 2013; Lee et al., 2014; Mncwangi et al., 2014). In recent years the near infrared spectroscopy (NIRS) was employed with linear

\footnotetext{
${ }^{*}$ Corresponding author:

Christos S. Pappas, Department of Food Science \& Human Nutrition, Laboratory of Chemistry, School of Food, Biotechnology and Development, Agricultural University of Athens, 75 lera Odos, 11855 Athens, Greece, China. E-mail: sqzhang@ms.iswc.ac.cn
}

Received: 14 November 2016; Revised: 05 January 2017; Accepted: 07 January 2017; Published Online: 14 January 2017 
and nonlinear regressions tools for the determination of antioxidant activity in green tea (Chen Q et al., 2012), in bamboo leaf extract (Wu et al., 2012), and in Salvia miltiorrbiza (Duan et al., 2014). Mid infrared spectroscopy (MIRS) in combination with multivariate analysis tools has recently been used for the study of antioxidant activity in propolis (Mot et al., 2011), in phosphorylated chitosan (Subhapradha et al., 2013), in sulphated polysaccharides (Li and Shah, 2014), in tea polysaccharides (Zhao et al., 2014), and in extracts from edible mushrooms (Ren et al., 2014).

The attenuated total reflectance (ATR)-FTIR spectroscopy is an interesting technique that is increasingly used in recent years (Karoui et al., 2010; Wang and Rodriguez-Saona, 2012; Helmdach et al., 2013; Cozzolino et al., 2014). The above spectroscopic technique combined with multivariate analysis was used for the determination of the total antioxidant capacity of red wine samples (Versari et al., 2009).

The aim of this work is to develop an alternative methodology for the antioxidant activity estimation, according to DPPH and ABTS assays, of various herbal infusions for routine analysis. The proposed methods combine the ATR-FTIR and the partial least squares (PLS) regression. The proposed methods are simple, fast and economical.

\section{MATERIALS AND METHODS}

\section{Materials}

For mixed herbal infusions we used the following: Seven commercial products of mixed herbals such as rosemarythyme (of biological and conventional cultivation), sagelemon verbena, cinnamon-clove, honey-orange, green tea-ginger-licorice, black tea-lemon-spearmint and seven non-mixed commercial products of spearmint, sage, lemon verbena and plant material of black tea from Trapezounta (Turkey, 2013 yield), oregano from Kalamata (Greece, 2013 yield), rosemary from Olympic village-Athens (Greece, 2013 yield) and thyme from Agrinio (Greece, 2013 yield). Furthermore a set of five samples which were prepared by mixing the above samples. A total of 19 samples were studied.

For DPPH assay: DPPH Sigma Aldrich, ethanol $99.8 \%$ Merck.

For the ABTS assay: ABTS Sigma Aldrich, $\mathrm{K}_{2} \mathrm{~S}_{2} \mathrm{O}_{8}$ Sigma Aldrich.

Trolox Sigma Aldrich.
Determination of the antioxidant activity using the DPPH and ABTS assays

Mixed herbal infusions were prepared by adding $2 \mathrm{~g}$ of each mixed herbal samples in $200 \mathrm{~mL}$ (about 1 cup) deionized hot water $\left(85^{\circ} \mathrm{C}\right)$ and steeped for five minutes. The herbal infusions were then filtered through a Whatman filter No. 1. Prior to analysis, an aliquot was further filtrated with a polytetrafluoroethylene filter with $0.45 \mu \mathrm{m}$ pore size. Then, the infusions were examined for their antioxidant activity with the methods of DPPH (Brand-Williams et al., 1995) and ABTS (Re et al., 1999). The antioxidant activity of each sample was expressed in $\mu \mathrm{mol} / \mathrm{mL}$ of Trolox. The measured Trolox values will be called actual values.

\section{FT-IR spectroscopy}

FT-IR spectra of the 19 samples were obtained in ATR mode using a standard $\mathrm{ZnSe} 45^{\circ}$ flat plate against a $\mathrm{ZnSe}$ background on a Nicolet 6700 FT-IR (Thermo Electron Corporation) spectrometer (Deuterated TriGlycine Sulfate detector; Nichrome source; KBr beamsplitter), with a total of 100 scans (resolution, $4 \mathrm{~cm}^{-1}$ ). A sample of $750 \mu \mathrm{L}$ was added from every herbal infusion in $\mathrm{ZnSe}$ plates. The samples were left to dry for approximately an hour and a half in the oven in $40^{\circ} \mathrm{C}$. Every spectrum was smoothed using the Savitsky-Golay algorithm (5-point moving, second-degree polynomial). Then the baseline was corrected (second-degree polynomial, 20 iterations). The OMNIC 7.3 (Thermo Fisher Scientific Inc.) software, that accompanies the spectrophotometer, was used for the previous functions.

\section{Chemometrics}

Two PLS models were developed using the TQ analyst software (version 8.0.0.245; Thermo Fisher Scientific Inc.) The first PLS model relating the estimation of antioxidant activity in accordance with DPPH assay and the second to ABTS assay. For this purpose the spectral region $1538-843 \mathrm{~cm}^{-1}$ in $2^{\text {nd }}$ derivative mode and the actual Trolox values, according to DPPH and ABTS assays, were used. The actual Trolox values and the corresponding spectra were entered in TQ analyst software to develop the PLS models. The 19 samples were split into two sets randomly by the software (Chen Y et al., 2012). The first set of 14 samples was used for the calibration of the PLS model and the second of five samples for the validation of the model. Two linear calibrations model were built as follows. The PLS model correlated the actual Trolox values with the corresponding spectral data and it calculated the new Trolox values (calculated values). The first PLS model concerns the Trolox values according to the DPPH assay, and the second to the ABTS assay. The optimum number of PLS factors was determined by the leave-one-out crossvalidation procedure. Three factors were used for $\mathrm{DPPH}-$ PLS model and six for ABTS. The existence of outliers 
was examined in calibrations data according to Chauvenet test and Leverage diagnostic on basis of spectral or Trolox actual values difference. The correlation coefficient $\left(\mathrm{R}^{2}\right)$, root-mean-square error of validation (RMSECV), and root-mean-square error of prediction (RMSEP) for each PLS model were calculated.

\section{RESULTS AND DISCUSSION}

\section{Antioxidant activity according to DPPH and ABTS assays}

The antioxidant activity of the 19 herbal infusions was determined using the DPPH and ABTS assays (Tables 1 and 2). The values, called actual, were ranged between 2470 (oregano) -580 (cinnamon-clove) $\mu \mathrm{mol} / \mathrm{mL}$ of Trolox for the DPPH assay and 4680 (oregano) - 200 (thyme) $\mu \mathrm{mol} / \mathrm{mL}$ of Trolox for the ABTS assay.

\section{Spectroscopic analysis}

Typical ATR-FTIR spectra of some herbal infusions are shown in Fig. 1. The peaks at $3400-3100 \mathrm{~cm}^{-1}$ correspond to $-\mathrm{OH}$ bond (Boeriu et al., 2004), 2970-2900 $\mathrm{cm}^{-1}$ to the C-H stretching (Boeriu et al., 2004), $1740-1720 \mathrm{~cm}^{-1}$ to $\mathrm{C}=\mathrm{O}$ stretching (Boeriu et al., 2004), 1620-1590 $\mathrm{cm}^{-1}$ to the aromatic $\mathrm{C}=\mathrm{C}$ stretching (Lu et al., 2011), 1410-1390 $\mathrm{cm}^{-1}$ mainly to $-\mathrm{CH}_{3}$ asymmetric deformation (Lu et al., 2011), $1270-1220 \mathrm{~cm}^{-1}$ to the C-O stretching of glycosides (Liu et al., 2012). Finally the peak at $1000-1300 \mathrm{~cm}^{-1}$ correspond to the combination of $\mathrm{C}-\mathrm{OH}$ hydrogen bond with $\mathrm{C}-\mathrm{OH}$ oligosaccharides and $\mathrm{C}-\mathrm{O}$ stretching coupled with $\mathrm{C}-\mathrm{O}$ bending of $\mathrm{C}-\mathrm{OH}$ of carbohydrates (Lu et al., 2011).
The antioxidant activity has been correlated with the presence of various phenolic compounds linked, or not, with sugars (Boskou, 2006; Kamiloglu et al., 2014; Vallverdu-Quevalt et al., 2014). The above compounds mainly absorb in the $1600-800 \mathrm{~cm}^{-1}$ spectral region. The spectra in this spectral region are very similar. So the 1538$843 \mathrm{~cm}^{-1}$ spectral region in $2^{\text {nd }}$ derivative mode has been selected (Ritthiruandej et al., 2011).

\section{Chemometrics}

TQ analyst software is a commercial package for multivariate analysis particularly user friendly. In the last years many works have been published describing PLS models using the TQ analyst software and the ATR spectroscopy (Kandhro et al., 2013; Jawaid et al., 2013; Kaya-Celiker et al., 2014; Silva et al., 2014; Talpur et al., 2014).

For the developing of the PLS models the actual values of Trolox and the corresponding ATR-FTIR spectra were combined using the TQ analyst software. Then the $1538-843 \mathrm{~cm}^{-1}$ spectral region in $2^{\text {nd }}$ derivative mode was chosen.

The software divided the samples in two sets automatically (Shen et al., 2011; Chen Y et al., 2012). A set of 14 samples was used for the calibration and another of five samples for the validation.

The statistical approach followed in this work is based on the linear combination of spectroscopic variables, so-called factors. A factor is a set of components that contains

Table 1: Antioxidant activity and the recovery of the different mixed herbal infusions with the DPPH assay (actual values) and with the proposed PLS - ATR-FTIR method (calculated values)

\begin{tabular}{lccc}
\hline Mixed herbal infusions & $\begin{array}{c}\text { Actual value } \\
(\mu \mathrm{mol} \text { Trolox/mL) }\end{array}$ & $\begin{array}{c}\text { Calculated value } \\
(\mu \mathrm{mol} \text { Trolox/mL) }\end{array}$ & Recovery $(\%)$ \\
\hline Bio rosemary-thyme & 1490 & 1351 & 1361 \\
Rosemary-thyme & 1280 & 586 & 106.3 \\
Cinnamon-clove & 580 & 1738 & 101.0 \\
Sage-lemon verbena & 1670 & 769 & 104.1 \\
Honey-orange & 790 & 2470 & 97.3 \\
Green tea-ginger-licorice & 2170 & 1868 & 113.8 \\
Black tea-lemon-spearmint & 2040 & 1156 & 91.6 \\
Spearmint & 1100 & 2119 & 105.1 \\
Thyme & 2180 & 1667 & 97.2 \\
Sage & 1680 & 644 & 99.2 \\
Rosemary & 630 & 1547 & 102.2 \\
Lemon verbena & 1590 & 818 & 97.3 \\
Black tea & 820 & 2395 & 99.8 \\
Oregano & 2470 & 1996 & 97.0 \\
Oregano - black tea & 1871 & 1261 & 106.7 \\
Rosemary - lemon verbena & 1391 & 2102 & 90.7 \\
Thyme - sage & 2123 & 1334 & 99.0 \\
Sage - lemon verbena - honey - orange & 1432 & 720 & 93.2 \\
Rosemary - thyme - cinnamon - clove & 818 & & 88.0 \\
\hline
\end{tabular}



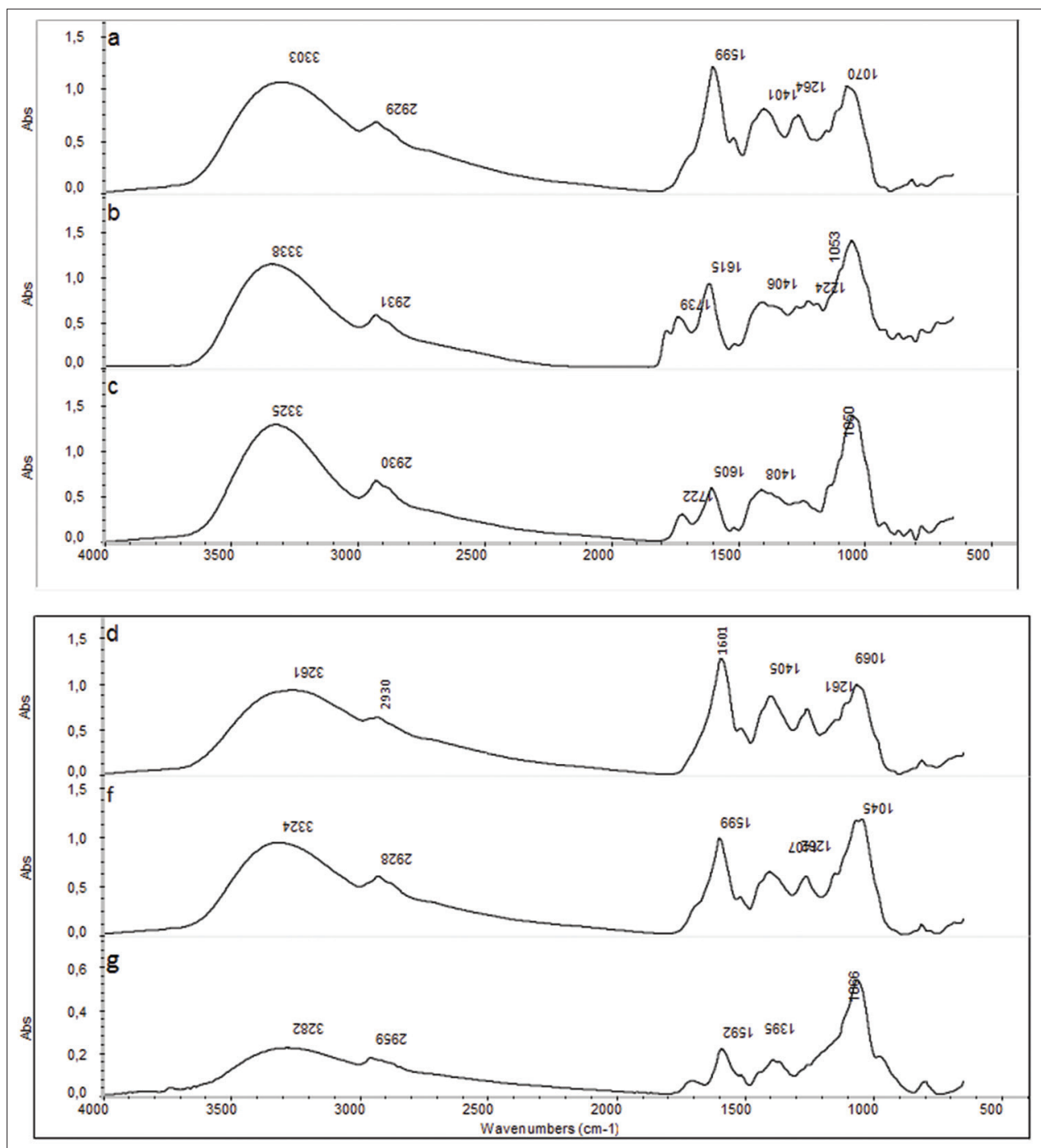

Fig 1. FT-IR spectra of the mixed herbal infusions: a) Sage - lemon verbena, b) cinnamon - clove, c) honey - orange, d) spearmint, f) lemon verbena g) rosemary.

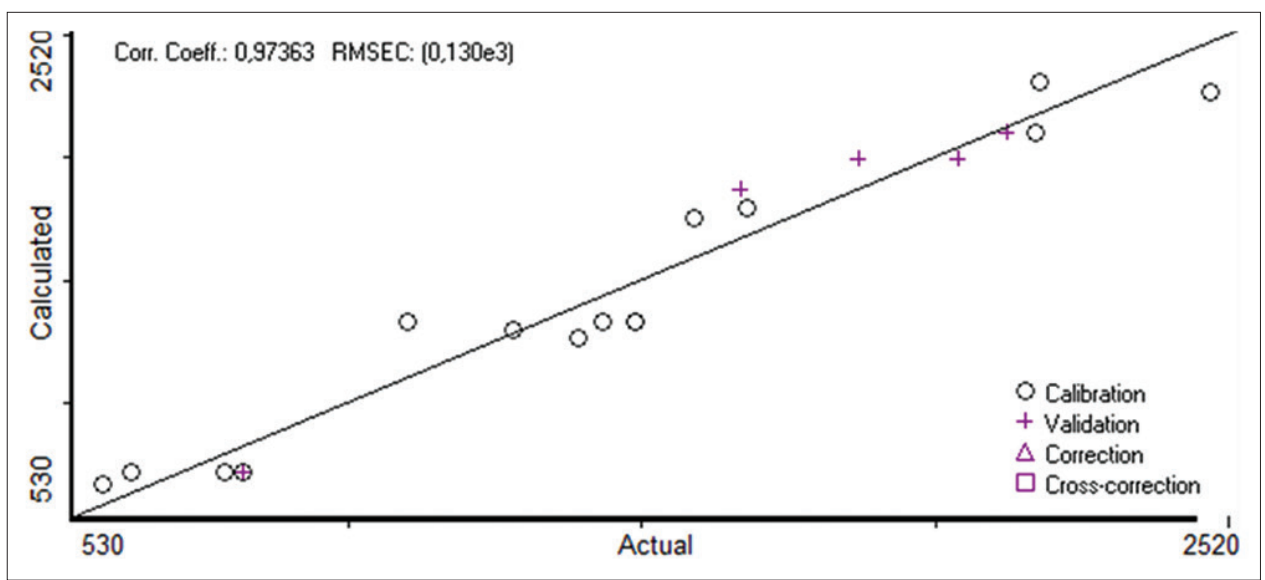

Fig 2. The linear correlation between the antioxidant activity according to the DPPH assay and proposed ATR-FTIR-PLS method. Correlation coefficient and RMSEC are also given.

spectral and actual values of Trolox information and it is used to describe the variation in a PLS method model.
The optimum number of the factors was determined using of leave-one-out cross validation by plotting the 
number of factors against the root mean square error cross validation (RMSECV) and determining the minimum factors. So for the DPPH determination were used three factors (RMSECV=241.7) (Fig. 2, Table 3) and for ABTS six (RMSECV=753.3) (Fig. 3, Table 3).

Outliers were detected on the basis of spectral or Trolox concentration difference with two widely used methods, Chauvenet test and Leverage diagnostic (Chen Y et al., 2012). Outliers not found.

Calibration evaluation was done using the RMSEC and determination coefficients. The RMSEC correlated with the differences between the actual Trolox values and the corresponding calculated, based on the FTIR spectra, values for the calibration set. The correlation coefficients $\left(\mathrm{R}^{2}\right)$ show how close the calculated with the actual values are. So for the DPPH evaluation $\mathrm{R}^{2}=0.97$ and RMSEC $=130$ (Fig. 2, Table 3). For the ABTS evaluation the corresponding values were found 0.99 and 148 respectively (Fig. 3, Table 3). These values show a very good linear correlation between the actual and calculated Trolox values for both evaluations. Furthermore the low RMSEC values, compared with the corresponding actual Trolox values, show that the calibration models are very satisfactory.

The RMSEP is associated with the differences between the actual and the predicted values by the model. The RMSEP values were found 118 for the DPPH-PLS model and 121 the corresponding ABTS-PLS (Table 3). The above values are low compared with the corresponding actual Trolox values.

The RMSEC and RMSEP values are closed together on each proposed PLS model. This observation coupled with the low values of RMSEC, RMSEP and the high $\mathrm{R}^{2}$ show the robustness of the proposed models (Chen Y et al., 2012; Kandhro et al., 2013).
Table 2: Antioxidant activity and the recovery of the different mixed herbal infusions with the ABTS assay (actual values) and with the proposed ATR-FTIR-PLS method (calculated values)

\begin{tabular}{|c|c|c|c|}
\hline $\begin{array}{l}\text { Mixed herbal } \\
\text { infusions }\end{array}$ & $\begin{array}{c}\text { Actual } \\
\text { value }(\mu \mathrm{mol} \\
\text { Trolox } / \mathrm{mL}) \\
\end{array}$ & $\begin{array}{c}\text { Calculated } \\
\text { value }(\mu \mathrm{mol} \\
\text { Trolox } / \mathrm{mL}) \\
\end{array}$ & $\begin{array}{l}\text { Recovery } \\
\text { (\%) }\end{array}$ \\
\hline Bio rosemary-thyme & 1790 & 1820 & 101.7 \\
\hline Rosemary-thyme & 1630 & 1413 & 86.7 \\
\hline Cinnamon-clove & 1110 & 1161 & 104.6 \\
\hline $\begin{array}{l}\text { Sage-lemon } \\
\text { verbena }\end{array}$ & 1880 & 2038 & 108.4 \\
\hline Honey-orange & 1340 & 1273 & 95.0 \\
\hline $\begin{array}{l}\text { Green } \\
\text { tea-ginger-licorice }\end{array}$ & 1730 & 1718 & 99.3 \\
\hline $\begin{array}{l}\text { Black } \\
\text { tea-lemon-spearmint }\end{array}$ & 3260 & 2850 & 87.4 \\
\hline Spearmint & 2130 & 2043 & 95.9 \\
\hline Thyme & 200 & 231 & 115.5 \\
\hline Sage & 2510 & 2052 & 81.8 \\
\hline Rosemary & 820 & 1107 & 135.0 \\
\hline Lemon verbena & 1800 & 1764 & 98.0 \\
\hline Black tea & 1260 & 1233 & 97.9 \\
\hline Oregano & 4680 & 4710 & 100.6 \\
\hline Oregano - black tea & 3181 & 2850 & 89.6 \\
\hline $\begin{array}{l}\text { Rosemary - lemon } \\
\text { verbena }\end{array}$ & 1794 & 1358 & 75.7 \\
\hline Thyme - sage & 1317 & 1519 & 115.3 \\
\hline $\begin{array}{l}\text { Sage - lemon } \\
\text { verbena - honey - } \\
\text { orange }\end{array}$ & 2112 & 2052 & 97.2 \\
\hline $\begin{array}{l}\text { Rosemary - thyme - } \\
\text { cinnamon - clove }\end{array}$ & 1235 & 1251 & 101.3 \\
\hline
\end{tabular}

Table 3: The PLS regression results of the proposed FTIR models for the estimation of the antioxidant activity according to DPPH, ABTS assays using the $1538-843 \mathrm{~cm}^{-1}$ spectral region in $2^{\text {nd }}$ derivative mode

\begin{tabular}{lccccc}
\hline $\begin{array}{l}\text { Proposed } \\
\text { method }\end{array}$ & $\mathbf{R}^{2}$ & RMSECV & Factors & RMSEC & RMSEP \\
\hline $\begin{array}{l}\text { DPPH } \\
\text { estimation }\end{array}$ & 0.97 & 241.7 & 3 & 130 & 118 \\
$\begin{array}{l}\text { ABTS } \\
\text { estimation }\end{array}$ & 0.99 & 753.3 & 6 & 148 & 121 \\
\hline
\end{tabular}

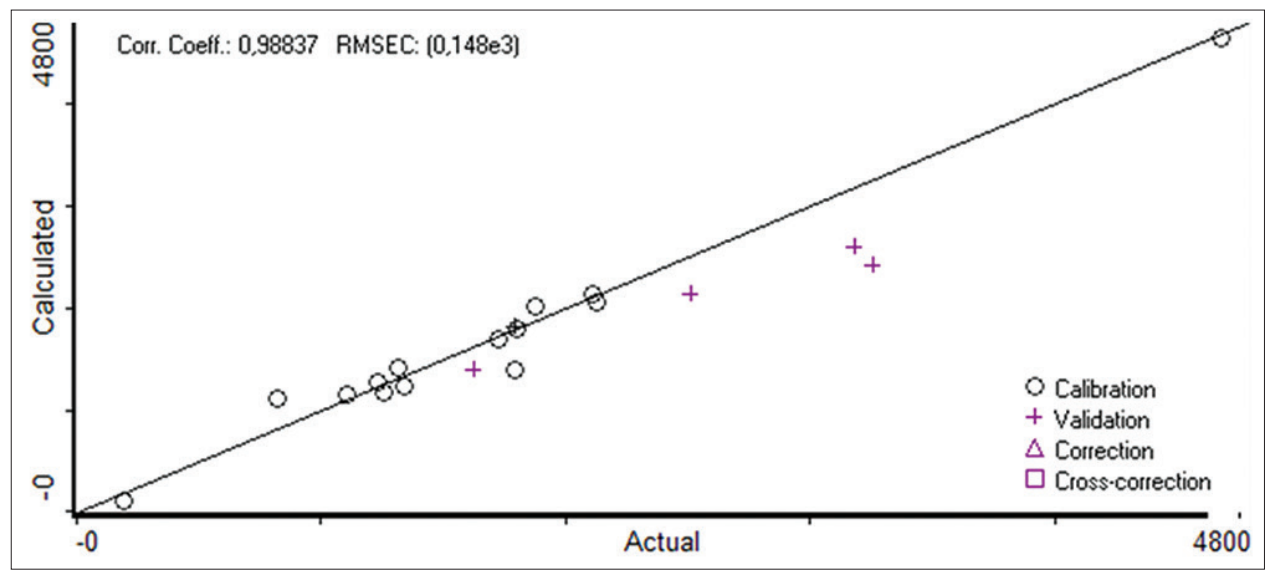

Fig 3. The linear correlation between the antioxidant activity according to the ABTS assay and proposed ATR-FTIR-PLS method. Correlation coefficient and RMSEC are also given. 
The Trolox values for the DPPH assay as they were calculated by the proposed ATR-FTIR-PLS method fluctuated from 2470 (green tea-ginger-licorice) to 586 (cinnamon-clove) $\mu \mathrm{mol} / \mathrm{mL}$ (Table 1). For the ABTS assay the calculated Trolox values were ranged between 4710 (oregano) and 231 (thyme) $\mu \mathrm{mol} / \mathrm{mL}$ (Table 2).

The recovery was calculated and its value was oscillated between 88.0 and $113.8 \%$ for the DPPH assay (Table 1). Each recovery value is between 80 and $120 \%$, which are the generally accepted limits. In case of ABTS assay (Table 2), only two values are outside the generally accepted limits. Hence the variability of the recovery value is considered satisfactory.

\section{CONCLUSION}

In this work two ATR-FTIR-PLS methods are proposed for the estimation of the antioxidant activity in different herbal infusions according to DPPH and ABTS. The proposed models are based on the ATR-FTIR spectroscopy. The spectral region $1538-843 \mathrm{~cm}^{-1}$ in $2^{\text {nd }}$ derivative mode and the PLS regression were used. The $\mathrm{R}^{2}$, RMSEC RMSEP and recovery values show that the proposed methods can be applied in routine analysis for the estimation of the antioxidant activity. In addition the proposed methods are simple, non time-consuming and economical.

\section{Author's contributions}

All authors contributed equally in this article.

\section{REFERENCES}

Aktumsek, A., G. Zengin, G. O. Guler, Y. S. Cakmak and A. Duran. 2013. Assessment of the antioxidant potential and fatty acid composition of four Centaurea $L$. Taxa from Turkey. Food Chem. 141(1): 91-97.

Atoui, A. K., A. Mansouri, G. Boskou and P. Kefalas. 2005. Tea and herbal infusions: Their antioxidant activity and phenolic profile. Food Chem. 89: 27-36.

Boeriu, C. G., D. Bravo, R. J. A. Gosselink and J. E. G. Van Dam. 2004. Characterization of structure-dependent functional properties of lignin with infrared spectroscopy. Ind. Crop Prod. 20: 205-218.

Boskou, D. 2006. Sources of natural phenolic antioxidants. Trends Food Sci. Technol. 17: 505-512.

Brand-Williams, W., M. E. Cuvelier and C. Berset. 1995. Use of a free radical method to evaluate antioxidant activity. Food Sci. Technol. 28(1): 25-30.

Chen, Q., Z. Guo, J. Zhao and Q. Quyang. 2012. Comparisons of different regressions tools in measurement of antioxidant activity in green tea using near infrared spectroscopy. J. Pharm. Biomed. 60: 92-97.

Chen, Y., M. Xie, H. Zhang, Y. Wang, S. Nie and C. Li. 2012. Quantification of total polysaccharides and triterpenoids in Ganoderma lucidum and Ganoderma atrum by near infrared spectroscopy and chemometrics. Food Chem. 135: 268-275.
Cozzolino, D., S. Roumeliotis and J. Eglinton. 2014. An attenuated total reflectance mid infrared (ATR-MIR) spectroscopystudy of gelatinization in barley. Carbohydr. Polym. 108: 266-271.

Duan, X., D. Zhang, L. Nie, H. Zang. 2014. Rapid discrimination of geographical origin and evaluation of antioxidant activity of Salvia miltiorrhiza var. alba by Fourier transform near infrared spectroscopy. Specrochim. Acta A Mol. Biomol. Spectrosc. 122: 751-757.

Dhar, P., A. B. Tayade, P. K. Bajpai, V. K. Sharma, S. K. Das, O. P. Chaurasia, R. B. Srivastava and S. B. Singh. 2012. Antioxidant capacities and total polyphenol contents of hydroethanolic extract of phytococktail from trans-Himalaya. J. Food Sci. 77(2): C156-C161.

Joshi, M., P. Aldred, S. McKnight, J. F. Panozzo, S. Kasapis, R. Adhikari and B. Adhikari. 2013. Physicochemical and functional characteristics of lentil starch. Carbohydr. Polym. 92: 1484-1496.

Fagan, C. C., C. P. O'Donnell, D. J. O'Callaghan, G. Downey, E. M. Sheehan, C. M. Delahynty, C. Everard, T. P. Guinee and V. Howard. 2007. Application of mid-infrared spectroscopy to the prediction of maturity and sensory texture attributes of cheddar cheese. J. Food Sci. 72(3): E130-E137.

Ferreira, D. S., O. F. Galao, J. A. L. Pallone and R. J. Poppi. 2014. Comparison and application of near-infrared (NIR) and midinfrared (MIR) spectroscopy for determination of quality parameters in soybean samples. Food Control. 35: 227-232.

Fu, H. Y., D. C. Huang, T.M. Yang, Y.B. She and H. Zhang. 2013. Rapid recognition of Chinese herbal pieces of Areca catechu by different concocted processes using Fourier transform mid-infrared and near-infrared spectroscopy combined with partial least-squares discriminant analysis. Chin. Chem. Lett. 24: 639-642.

Helmdach, L., M. P. Feth, C. Minnich and J. Ulrich. 2013. Application of ATR-MIR spectroscopy in the pilot plant-scope and limitations using the example of paracetamol crystallizations. Chem. Eng. Process. 70: 184-197.

Jawaid, S., F. N. Talpur, S. T. H. Sherazi, S. M. Nizamani and A. A. Khaskheli. 2013. Rapid detection of melamine adulteration in dairy milk by SB-ATR-Fourier transform infrared spectroscopy. Food Chem. 141: 3066-3071.

Kamiloglu, S., A. A. Pasli, B. Ozcelik and A. Capanoglu. 2014. Evaluating the in vitro bioaccessibility of phenolics and antioxidant activity during consumption of dried fruits with nuts. Food Sci. Technol 56: 284-289.

Kandhro, A. A., A. H. Laghari, S. A. Mahesar, R. Saleem, A. Nelofar, S. T. Khan and S. T. H. Sherazi. 2013. Application of attenuated total reflectance Fourier transform infrared spectroscopy for determination of cefixime in oral pharmaceutical formulations. Spectrochim. Acta A. 115: 51-56.

Karoui, R., G. Downey and C. Blecker. 2010. Mid-infrared spectroscopy coupled with chemometrics: A tool for the analysis of intact food systems and the exploration of their molecular structure-quality relationships - A review. Chem. Rev. 110: 6144-6168.

Kaya-Celiker, H., P. K. Mallikarjunan, D. Schmale III ${ }^{\text {rd }}$ and M. E. Christie. 2014. Discrimination of moldy peanuts with reference to aflatoxin using FTIR-ATR system. Food Control. 44: 64-71.

Khanmohammadi, M. and A. B. Garmarudi. 2011. Infrared spectroscopy provides a

green analytical chemistry tool for direct diagnosis of cancer. Trends Anal. Chem. 30(6): 864-874.

Lee, M. S., Y. S. Hwang, J. Lee and M. G. Choung. 2014. The characterization of caffeine and nine individual catechins in the leaves of green tea (Camellia sinensis L.) By near-infrared reflectance spectroscopy. Food Chem. 158: 351-357. 
Li, S and N. P. Shah. 2014. Antioxidant and antibacterial activities of sulphated polysaccharides from Pleurotus eryngii and Streptococcus thermophilus ASCC 1275. Food Chem. 165: 262-270.

Lou, S. N., Y. S. Lin, Y. S. Hsu, E. M. Chiu and C. T. Ho. 2014. Soluble and insoluble phenolic compounds and antioxidant activity of immature calamondin affected by solvents and heat treatment. Food Chem. 161: 246-253.

Lu, X., J. Wang, H. M. Al-Qadiri, C. F. Ross, J. R. Powers, J. Tang and B. A. Rasco. 2011. Determination of total phenolic content and antioxidant capacity of onion (Allium cepa) and shallot (Allium oschaninii) using infrared spectroscopy. Food Chem. 129: 637-644.

Mot, A. C., R. Silaghi-Dumitrescu and C. Sarbu. 2011. Rapid and effective evaluation of the antioxidant capacity of propolis extracts using DPPH bleaching kinetic profiles, FT-IR and UV-vis spectroscopic data. J. Food Compost. Anal. 24: 516-522.

Mncwangi, N., I. Vermaak and A. M. Viljoen. 2014. Mid-infrared spectroscopy and short wave infrared hyperspectral imaging-A novel approach in the qualitative assessment of Harpagophytum procumbens and $H$. zeyheri (Devil's claw). Phytochem. Lett. 7: 143-149.

Pincemail, J., J. C. Kevers, J. Tabart, J. O. Defraigne and J. Dommes. 2012. Cultivars, culture conditions, and harvest time influence phenolic and ascorbic acid contents and antioxidant capacity of strawberry (Fragaria $x$ ananassa). J. Food Sci. 77(2): 205-210.

Rautenbach, F. and I. Venter. 2013. Hydrophilic and lipophilic antioxidant capacity of commonly consumed South African fruits, vegetables, grains, legumes, fats/oils and herbal infusions. J. Food Compost. Anal. 23: 753-761.

Rautiainen, S., E. B. Levitan, M. A. Mittleman and A. Wolk. 2013. Total antioxidant capacity of diet and risk of heart failure: A population-based prospective cohort of women. Am. J. Med. 126: 494-500.

Re, R., N. Pellegrini, A. Proteggente, A. Pannala, M. Yang and C. Rice-Evans. 1999. Antioxidant activity applying an improved ABTS radical cation decolorization assay. Free Radic. Bio. Med. 26(9-10): 1231-1237.

Ren, L., Y. Hemara, C. O. Perera, G. Lewis, G. W. Krissansen and P. K. Buchanand. 2014. Antibacterial and antioxidant activities of aqueous extracts of eight edible mushrooms. Bioact. Carbohydr. Diet. Fibre. 3: 41-51.

Ritthiruangdej, P., R. Ritthiron, H. Shinzawa and Y. Ozaki. 2011. Non- destructive and rapid analysis of chemical compositions in Thai steamed pork sausages by near-infrared spectroscopy. Food Chem. 129: 684-692.

Saeidnia, S. and M. Abdollahi. 2013. Antioxidants: Friends or foe in prevention or treatment of cancer: The debate of the century. Toxicol. Appl. Pharm. 271: 49-63.

Silva, S. D., R. P. Feliciano, L. V. Boas and M. R. Bronze. 2014. Application of FTIR-ATR to Moscatel dessert wines for prediction of total phenolic and flavonoid contents and antioxidant capacity. Food Chem. 150: 489-493.

Shen, F., Y. Ying, B. Li, Y. Zheng and J. Hu. 2011. Prediction of sugars and acids in Chinese rice wine by mid-infrared spectroscopy. Food Res. Int. 44: 1521-1527.

Subhapradha, N., P. Ramasamy, S. Sudharsan, P. Seedevi, M. Moovendhan, A. Srinivasan, V. Shanmugam and A. Shanmugam. 2013. Preparation of phosphorylated chitosan from gladius of the squid Sepioteuthis lessoniana (Lesson, 1830 ) and its in vitro antioxidant activity. Bioact. Carbohydr. Diet. Fibre. 1: 148-155.

Talpur, M.Y., H. Kara, S. T. H. Sherazi, H. F. Ayyildiz, M. Topkafa, F. N. Arslan, S. Naz, F. Durmaz and H. Sirajuddin. 2014. Application of multivariate chemometric techniques for simultaneous determination of five parameters of cotton seed oil by single bounce attenuated total reflectance Fourier transform infrared spectroscopy. Talanta. 129: 473-480.

Vallverdu-Queralt, A., J. Regueiro, M. Martinez-Huelamo, J. F. R. Alvarenga, L. N. Leal and R. M. Lamuela-Raventos. 2014. A comprehensive study on the phenolic profile of widely used culinary herbs and spices: Rosemary, thyme, oregano, cinnamon, cumin and bay. Food Chem. 154: 299-307.

Versari, A., G. P. Parpinello, F. Scazzina and D. D. Rio. 2009. Prediction of total antioxidant capacity of red wine by Fourier transform infrared spectroscopy. Food Control. 21: 786-789.

Wang, T. and L. E. Rodriguez-Saona. 2012. Rapid determination of sugar level in snack products using infrared spectroscopy. J. Food Sci. 77(8): C874-C879.

Wu, D., J. Chen, B. Lu, L. Xiong, Y. He and Y. Zhang. 2012. Application of near infrared spectroscopy for the rapid determination of antioxidant activity of bamboo leaf extract. Food Chem. 135: 2147-2156.

Zhao, Z. Y., L. T. Huangfu, L. L. Dong and S. L. Liu. 2014. Functional groups and antioxidant activities of polysaccharides from five categories of tea. Ind. Crop Prod. 58: 31-35. 